\title{
HESS Opinions: Beyond the long-term water balance: evolving Budyko's supply-demand framework for the Anthropocene towards a global synthesis of land-surface fluxes under natural and human-altered watersheds
}

\author{
A. Sankarasubramanian ${ }^{1}$, Dingbao Wang ${ }^{2}$, Stacey Archfield ${ }^{3}$, Meredith Reitz ${ }^{3}$, Richard M. Vogel ${ }^{4}$, \\ Amirhossein Mazrooei $^{1}$, and Sudarshana Mukhopadhyay ${ }^{1}$ \\ ${ }^{1}$ Department of Civil, Construction and Environmental Engineering, \\ North Carolina State University, Raleigh, NC 27695, USA \\ ${ }^{2}$ Department of Civil, Environmental, and Construction Engineering, University of Central Florida, Orlando, FL 32816, USA \\ ${ }^{3}$ US Geological Survey, Water Mission Area, Reston, VA 20192, USA \\ ${ }^{4}$ Department of Civil and Environmental Engineering, Tufts University, Medford, MA 02155, USA
}

Correspondence: A. Sankarasubramanian (sankar_arumugam@ncsu.edu)

Received: 8 August 2019 - Discussion started: 13 September 2019

Revised: 5 February 2020 - Accepted: 20 March 2020 - Published: 17 April 2020

\begin{abstract}
Global hydroclimatic conditions have been substantially altered over the past century by anthropogenic influences that arise from the warming global climate and from local/regional anthropogenic disturbances. Traditionally, studies have used coupling of multiple models to understand how land-surface water fluxes vary due to changes in global climatic patterns and local land-use changes. We argue that because the basis of the Budyko framework relies on the supply and demand concept, the framework could be effectively adapted and extended to quantify the role of drivers - both changing climate and local human disturbances - in altering the land-surface response across the globe. We review the Budyko framework, along with these potential extensions, with the intent of furthering the applicability of the framework to emerging hydrologic questions. Challenges in extending the Budyko framework over various spatiotemporal scales and the use of global datasets to evaluate the water balance at these various scales are also discussed.
\end{abstract}

1 The historical evolution of the Budyko framework in hydroclimatology

The traditional Budyko formulation provides the long-term water balance as a simple but effective partitioning of precipitation into runoff and evapotranspiration, and it has been verified over numerous natural watersheds around the globe (Sankarasubramanian and Vogel, 2003; Zhang et al., 2004; Yang et al., 2007; Li et al., 2013; Padrón et al., 2017). Besides the aridity index, which is defined as the ratio of the mean annual potential evapotranspiration to the mean annual precipitation, Milly (1994) and Sankarasubramanian and Vogel (2002) proposed additional controls on the long-term water balance, including seasonality and soil moisture holding capacity. These additional controls enhance the ability of the Budyko framework to explain the spatial variability in mean annual runoff at the continental scale. Studies have also extended the Budyko framework for capturing the interannual variability in runoff (Koster and Suarez, 1999; Sankarasubramanian and Vogel, 2002, 2003). More recently, the Budyko framework has been extended for explaining the seasonal hydroclimatology of basins (Petersen et al., 2012, 2018; Chen et al., 2013). Similarly, the Budyko framework has been extended for quantifying the non-dimensional sensitivity (also termed elasticity) of land-surface response to 
changes in climatic controls under different hydroclimatic regimes (Dooge, 1992; Dooge et al., 1999; Sankarasubramanian et al., 2001).

Perhaps the most unusual aspect of the Budyko framework lies in its Darwinian approach, which enables us to view the entire hydroclimatic system without focusing on each physical process in isolation (Harman and Troch, 2014; Wang and Tang, 2014). The Darwinian approach seeks to document patterns of variation in populations of hydrologic systems and develop theories that explain these observed patterns in terms of the mechanisms and conditions that determine their historical development (Harman and Troch, 2014). Even though most studies which employed the Budyko framework have focused on natural basins, the original monograph (Budyko, 1974), Climate and Life, considered the role of human influence on climate, including effects of reservoir storage and irrigation on evapotranspiration. As hydroclimatic regimes evolve, it is critical to understand how land-surface fluxes change due to changes in local watershed conditions and global climate change. Given the Budyko framework's ability to capture the fundamental dimensions of land-surface fluxes, its emphasis on describing patterns of variation across differing hydrogeologic and hydroclimatic regimes, and, by extension, its emphasis on an integrative, Darwinian approach, a global synthesis addressing the variability in these fluxes across natural and human-altered watersheds should provide insights into the sensitivity of the critical hydroclimatic processes to local and global changes in the Anthropocene.

\section{Budyko framework for the Anthropocene}

We are at a critical time in which the hydroclimate, particularly land-surface fluxes, has been substantially altered over the past century by anthropogenic disturbances (Entekhabi et al., 1999; Vogel et al., 2015). For instance, both annual precipitation and streamflow have increased during the period of 1948-1997 across the eastern US, and those trends appear to arise primarily from increases in autumn precipitation (Small et al., 2006; Rice et al., 2015). Similarly, the frequency of floods is increasing in many regions, while magnitudes of flooding appear only to be systematically increasing in certain spatially cohesive regions (Hirsch and Archfield, 2015; Malikpour and Villarini, 2015; Archfield et al., 2016), particularly in urban areas (Vogel et al., 2011; Barros et al., 2014; Prosdocimi et al., 2015). Irrigation in the US High Plains leads to increases in summer rainfall and streamflow in the Midwest due to land-surface and atmosphere feedback (Kustu et al., 2011). Based on hydroclimatic observations from 100 large basins globally, Jaramillo and Destouni (2015) found consistent and dominant effects of increasing relative evapotranspiration (evapotranspiration relative to precipitation) from flow regulation and irrigation and decreasing temporal runoff variability from flow regu- lation. Development of irrigation networks and man-made reservoirs is also associated with increased surface water and groundwater withdrawals and land-use change (Dieter et al., 2018; Sankarasubramanian et al., 2017; Das et al., 2018). Similarly, construction of large dams has substantially altered the downstream flow variations affecting downstream ecology (Gao et al., 2009; Wang et al., 2017). Changes in land use and land cover also affect the local energy balance, creating urban heat islands (Memon et al., 2008) and affecting recharge and baseflow (Price, 2011), which in turn affect a very broad range of streamflows (Allaire et al., 2015) with particularly significant increases in high flows (Vogel et al., 2011; Barros et al., 2014; Prosdocimi et al., 2015). Thus, anthropogenic influences arising from global climate change and local to regional disturbances can substantially affect the land-surface response from the watershed. Anthropogenic influences, including changes in climate, land use, and water use, exhibit complex interactions that warrant consideration jointly to understand their effect on hydrologic flow alteration (Allaire et al., 2015). Performing a synthesis on how the spatio-temporal variability of land-surface fluxes - runoff, evapotranspiration, net radiation, and hydrologic flow alteration - differ globally in natural and human-altered watersheds is a critical need to enable a complete understanding of global hydroclimate during the Anthropocene. The Budyko framework provides an ideal approach for such inquiry, because it has been used to decompose changes in observed land-surface fluxes due to both natural variability and human influence (e.g., Roderick and Farquhar, 2011; Wang and Hejazi, 2011; Yang et al., 2014; Jiang et al., 2015).

\section{Budyko framework adaptation in watershed modeling}

Figure 1 provides the general setup of the Budyko framework for explaining the spatio-temporal variability of landsurface fluxes in natural watersheds and human-altered landscapes. The framework relies on conservation of mass and energy to model and predict the "actual" hydroclimatic variable of interest based on the available "demand" and "supply" of mass and energy (Fig. 1). The term "demand" is defined as the upper bound of the "actual" variable if the "supply" variable is unlimited. The rationale for using the Budyko framework for understanding the spatial variability in landsurface fluxes over natural/human-altered watersheds lies in its ability to capture the hydroclimatic dimensions of "supply" and "demand", thereby providing a low-dimensional parsimonious approach (Fig. 1) to understand the spatial variability in the "actual" hydroclimatic variable of interest. Even though Budyko's framework is commonly used to understand the long-term water balance, the supply-demand framework could be used for understanding the spatial variability of different land-surface fluxes. This study evaluates and extends the Budyko supply-demand framework for un- 


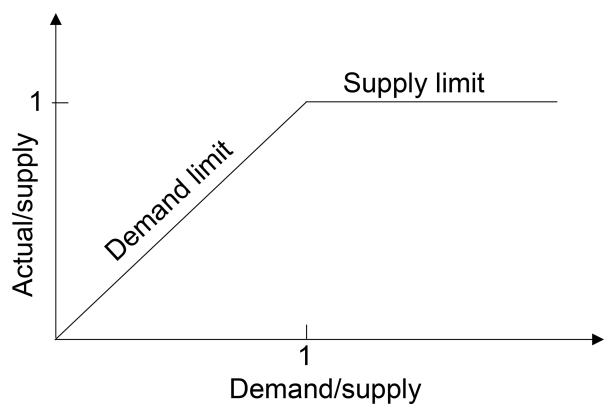

Figure 1. An overview of the Budyko supply and demand framework for understanding the land-surface flux response (actual) over natural and human-altered watersheds. The "limits" concept as suggested by Budyko (1958) quantifies the actual response ( $y$ axis) based on the physical demand-to-supply ratio of energy / moisture over the control volume or the watershed.

derstanding the spatio-temporal variability of two hydrologic fluxes, namely global evapotranspiration and water balance (Fig. 2), infiltration (Fig. 3) and three human-altered fluxes, namely reservoir releases using linear hedging (Fig. 4) and environmental flow alteration (Fig. 5).

\subsection{Long-term water balance}

The most commonly used framework for modeling the longterm water balance is to estimate the mean annual evapotranspiration ("actual") based on the ratio of mean annual potential evapotranspiration ("demand") to the mean annual precipitation ("supply"). Thus, the upper limit for mean annual evapotranspiration is potential evapotranspiration (precipitation) in a humid (arid) region. The family of Budyko curves estimates the evapotranspiration ratio ("actual" / "supply") based on the aridity index ("demand" / "supply"). For additional details, see Sankarasubramanian and Vogel (2001). Most studies have focused on evaluating the long-term water balance at regional and continental scales (see Wang et al., 2016, for a detailed review). Studies have also focused on the effect of land cover and climate on long-term water yield using global data (Li et al., 2013; Wang and Tang, 2014). Here, we evaluate the Budyko framework to the global scale using the data from the Global Land-Surface Data Assimilation System, version 2 (GLDAS2) (Rodell et al., 2004). Data points of mean annual evapotranspiration and aridity index are obtained using the Penman-Monteith method from the Noah Land Surface Model in the GLDAS2 dataset with a spatial resolution of $0.25^{\circ}$ for the period 1948-2010 (Rui, 2011). Figure 2 shows the performance of the Budyko curve in estimating the mean annual evapotranspiration based on aridity index data between $-60^{\circ} \mathrm{S}$ and $60^{\circ} \mathrm{N}$. The Budyko curve provides a first-order approximation of the spatial variability in the evapotranspiration ratio (Fig. 2); however, the scatter around the curve is quite considerable. The evapotranspiration ratios plotted in Fig. 2 have bias as they are based on Noah Land Surface Model estimates from the GLDAS2 model. For large basins, estimating evapotranspiration as the difference between precipitation and streamflow is more accurate as the ET ratio and aridity index are purely based on observed information (Sankarasubramanian and Vogel, 2003). Studies have shown that seasonality in moisture and energy and their co-availability (i.e., phase difference between moisture and energy availability within the year) and soil moisture holding capacity partially control the scatter around the Budyko curves (Milly, 1994; Sankarasubramanian and Vogel, 2003). Another question of interest is to understand the lower bound on the evapotranspiration ratio, which is typically limited by the moisture availability in a region (Wang and Tang, 2014). Numerous studies on long-term balance have employed fitting of the observed long-term water balance by parameterizing the Budyko curves (see the review paper of Wang et al., 2016). However, little to no effort has been undertaken on how this cloud of the longterm water balance is expected to change under potential climate change and how this interplay between moisture and energy is expected to affect the long-term water balance in different types of watersheds (Creed et al., 2014). Similarly, recent studies have extended Budyko's steady-state supplyto-demand framework for modeling land-surface fluxes over fine (daily and monthly) timescales (Zhang et al., 2008). Validating these emerging frameworks with global hydrologic data will provide an understanding of the critical process controls in estimating land-surface fluxes. This validation effort will also help in understanding the advantages and limitations of such a parsimonious modeling approach towards estimating evapotranspiration and streamflow at various spatio-temporal scales.

\subsection{Extension of Budyko's "supply and demand" concept for infiltration}

The upper bounds on the Budyko framework arise from the conservation of mass and energy. Hence, in principle, it could be applied to other hydrological processes. Zhang et al. (2008) applied the Budyko monthly supply and demand attributes to estimate the catchment retention and the overland runoff from the soil moisture zone. Wang (2018) developed the infiltration equation for saturation excess in the Budyko supply and demand framework, i.e., modeling the ratio of infiltration to rainfall depth as a function of the ratio between storage (infiltration) capacity and rainfall depth (Fig. 3). The cumulative infiltration depth during a rainfall event is defined as the "actual" variable of interest, and the cumulative rainfall depth during an event is defined as the "supply". The effective soil water storage capacity for the event is defined as the "demand", which is dependent on the initial soil moisture condition. Alternate definitions of storage capacity based on soil hydraulic equilibrium storage could also be considered (Zehe et al., 2019). 

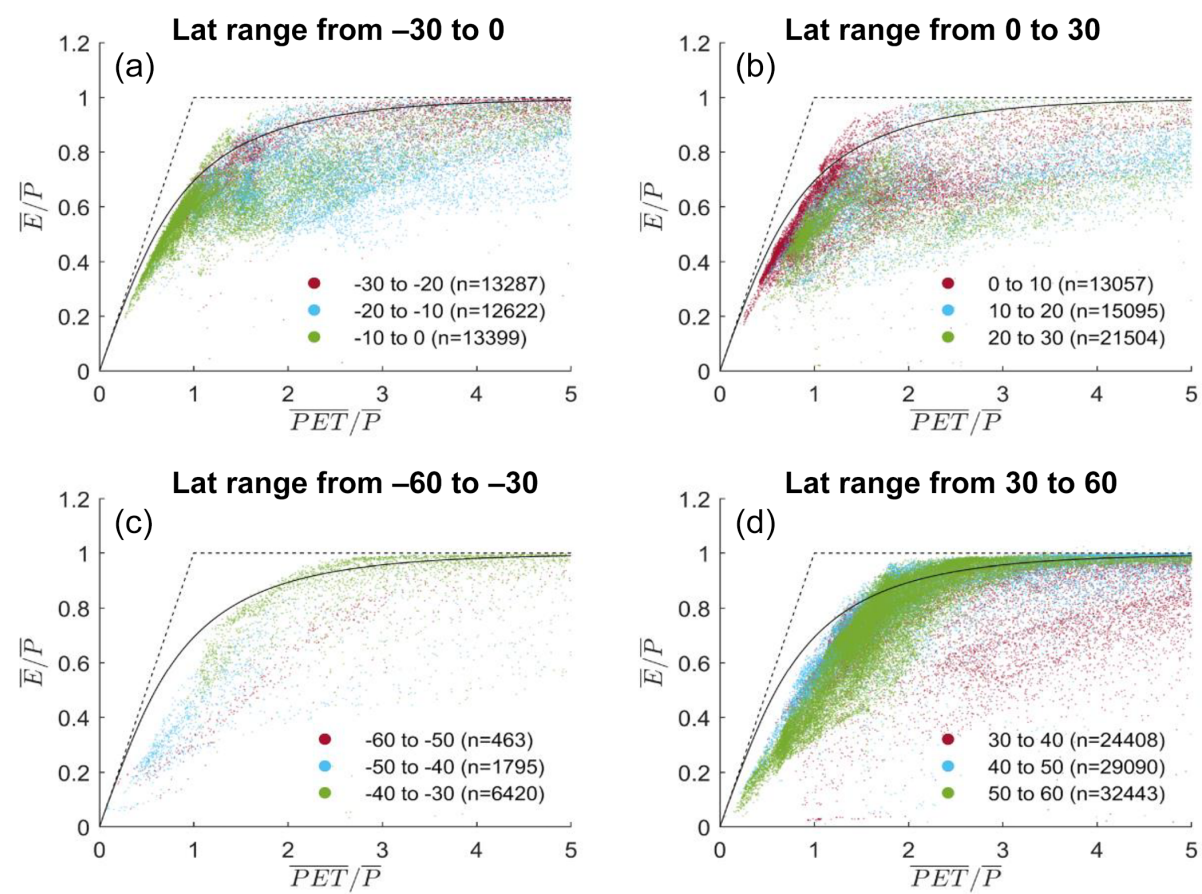

Figure 2. The traditional Budyko framework for long-term water balance along with the asymptotes and the Budyko curve $(\overline{\mathrm{ET}} / \bar{P}=$ $\left.\left[(1-\exp (-\overline{\mathrm{PET}} / \bar{P})) \cdot \overline{\mathrm{PET}} / \bar{P} \cdot \tanh (\overline{\mathrm{PET}} / \bar{P})^{-1}\right]^{0.5}\right)$. The ratio of mean annual potential evapotranspiration $(\overline{\mathrm{PET}}$, demand $)$ to mean annual precipitation $(\bar{P}$, supply) explains the ratio of mean annual evapotranspiration $(\overline{\mathrm{ET}}$, actual) and $\bar{P}$, and the data points are from GLDAS-2 estimates (Rodell et al., 2004) at the pixel level $\left(0.25^{\circ}\right)$ for the period 1948-2010 over the Northern Hemisphere (b, d, 0-30 and 30-60 latitudes) and Southern Hemisphere (a, c, $0-30$ and -30 to $-60^{\circ}$ latitudes).

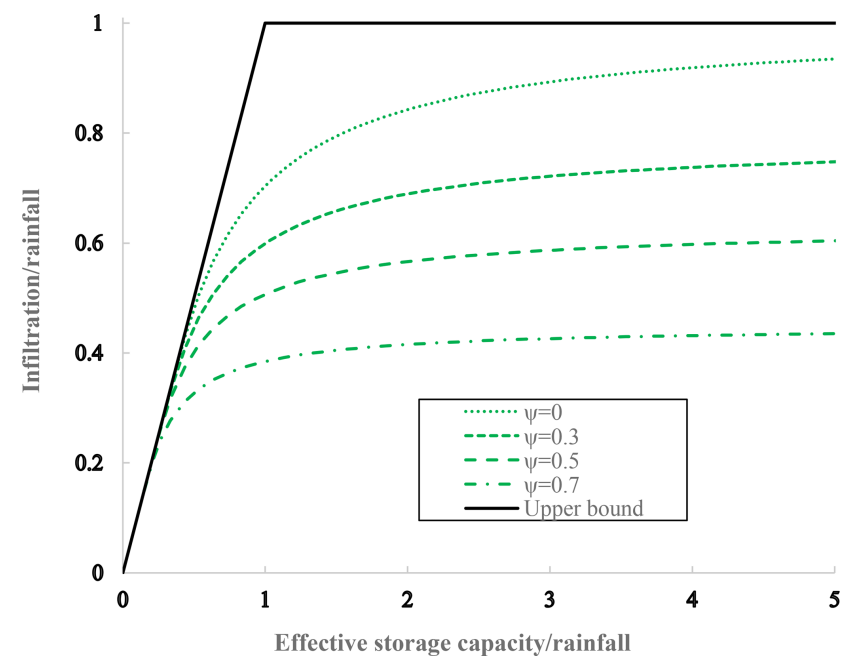

Figure 3. Modeling infiltration in the Budyko supply and demand framework: the ratio of infiltration (actual) and rainfall depth is a function of the ratio of infiltration capacity (demand) and rainfall depth (supply) as well as the initial soil moisture condition represented by the degree of saturation $(\psi)$ (reproduced from Wang, 2018).
Figure 3 represents the initial soil moisture condition by the degree of saturation, $\psi$, which is defined as the ratio of initial soil water storage and storage capacity (Wang, 2018). For a dry soil with low $\psi$, infiltration is expected to be higher with lower surface runoff potential. The upper bounds of these curves (Fig. 3) are similar to the Budyko asymptotes corresponding to infiltration capacity-limited and rainfall depth-limited conditions. In this illustration, the Budyko framework is extended to estimate the temporal variability of infiltration into the soil based on soil water storage capacity and antecedent conditions $(\psi)$. Thus, the parsimonious framework derived from the Budyko supply and demand concept is used to develop the asymptotes, and then those asymptotes are used to identify and explain various critical process controls (e.g., infiltration in Fig. 3).

Although the above extensions of the Budyko framework demonstrate the potential for developing a low-dimensional parsimonious modeling strategy, data-based validation efforts have focused primarily on the long-term hydroclimatic attributes (i.e., mean, variance and elasticity) of observed land-surface fluxes in natural basins (Fig. 2) (Sankarasubramanian and Vogel, 2002; Abatzoglou and Ficklin, 2017). Representing a hydroclimatic variable of interest (i.e., "actual") as a ratio to the "supply" and explaining its spatiotemporal variability based on the demand / supply ratio and other variables (e.g., soil moisture holding capacity for long- 


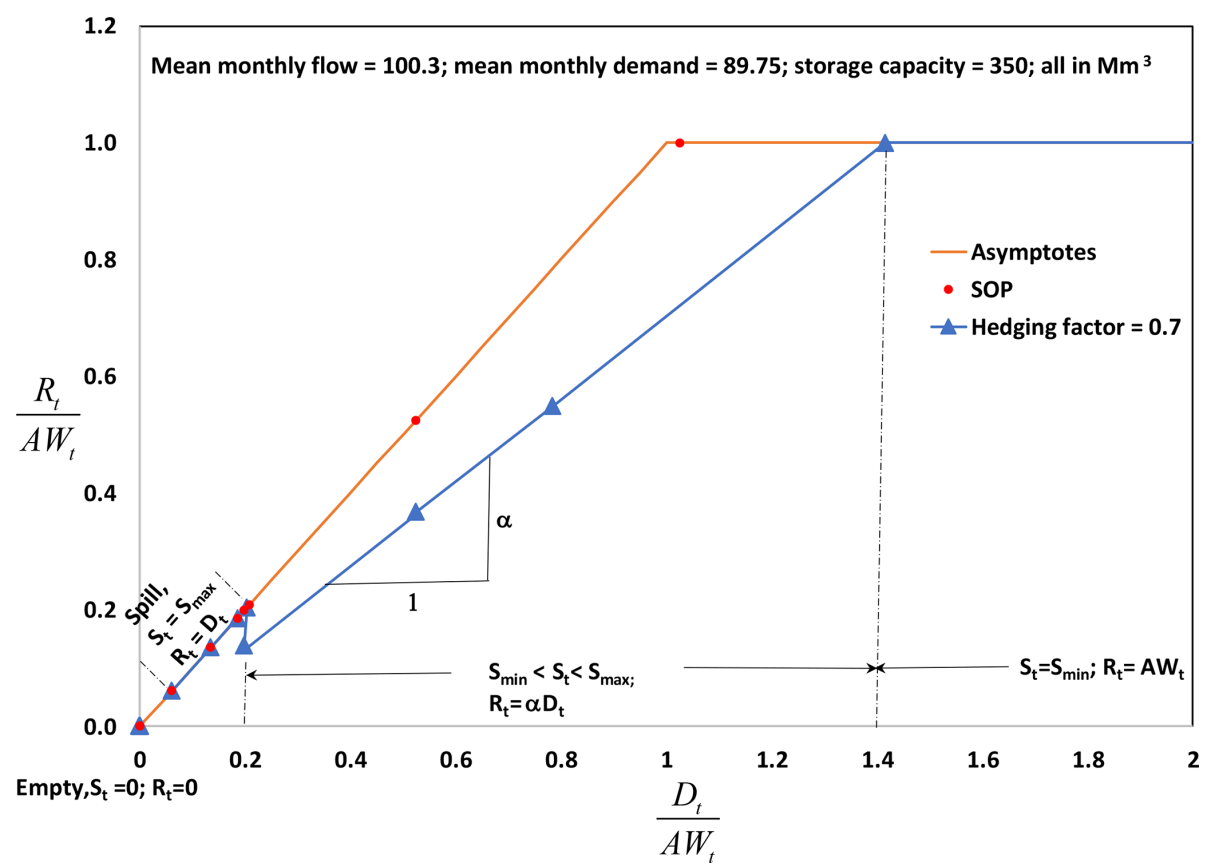

Figure 4. Modeling hedging policy of reservoir operations in the Budyko supply and demand framework. The standard operating policy (SOP) corresponds to the asymptotes. For the hedging rule, delivery or release is "actual", available water is "supply", and human use is "demand". For demonstration purposes, a linear function is assumed for the hedging rule (i.e., $R_{t}=\alpha D_{t}$ ). The storage conditions are indicated for the hedging policy alone.

term water balance) provides a simple, non-dimensional form for understanding the process controls. For instance, in the long-term water balance context, defining the demandsupply relationship explains the predominant controls on the spatio-temporal variability of mean annual runoff and mean annual evapotranspiration based on the basin aridity, seasonality of demand and supply attributes (i.e., in-phase or outof-phase between moisture and energy), and soil moisture holding capacity (Milly, 1994). Synthesizing relevant process controls and representing them within the Budyko lowdimensional framework will also help us in catchment classification and in understanding how different hydroclimatic processes of interest vary across wider regimes and landscapes.

\section{Extending Budyko framework for human-altered watersheds and landscapes}

Figures 4 and 5 extend the Budyko framework to explain the spatio-temporal variability in land-surface fluxes in humanaltered watersheds and landscapes. A synthesis that extends and evaluates the Budyko framework for estimating landsurface fluxes in human-altered watersheds will help us understand the role of key anthropogenic disturbances (e.g., reservoir storage, land-use and land-cover changes) in altering land-surface fluxes at various spatio-temporal scales.

\subsection{Extension of Budyko's "supply and demand" framework for reservoir operation and hedging}

We extend the Budyko framework for reservoir operation to meet the target demand based on the standard operating policy (SOP) and linear hedging policy (Draper and Lund, 2004). A hedging policy in reservoir operation aims to conserve water for future use by curtailing the current demand (Draper and Lund, 2004). Given an initial storage $\left(S_{t-1}\right)$, inflow $\left(I_{t}\right)$, demand $\left(D_{t}\right)$ and evaporation $\left(E_{t}\right)$ over a given time step $(t)$, one could obtain the actual release $\left(R_{t}\right)$ and ending storage $\left(S_{t}\right)$ along with spill $\left(\mathrm{SP}_{t}\right)$ using a mass balance (Eq. 1).

$S_{t}=S_{t-1}+I_{t}-E_{t}-R_{t}-\mathrm{SP}_{t}$

By defining available water, $\mathrm{AW}_{t}=S_{t-1}+I_{t}-E_{t}$, we obtain release (as "actual") under a given hedging fraction $(0 \leq \alpha \leq$ 1) for three reservoir storage conditions using Eq. (2). The SOP of a reservoir simply corresponds to $\alpha=1$ by supplying available water or demand at a given time.

$$
\begin{aligned}
S_{t}= & S_{\max }, R_{t}=D_{t}, \mathrm{SP}_{t}=\mathrm{AW}_{t}-D_{t}-S_{\max } \\
& \text { if } \mathrm{AW}_{t}-D \geq S_{\max } \\
S_{t}= & \mathrm{AW}_{t}-R_{t}, R_{t}=\alpha D_{t}, \mathrm{SP}_{t}=0 \\
& \text { if } S_{\min }<\mathrm{AW}_{t}-D_{t}<S_{\max } \\
S_{t}= & S_{\min }, R_{t}=\mathrm{AW}_{t}, \mathrm{SP}_{t}=0 \\
& \text { if } S_{\min } \geq \mathrm{AW}_{t}-D_{t}
\end{aligned}
$$




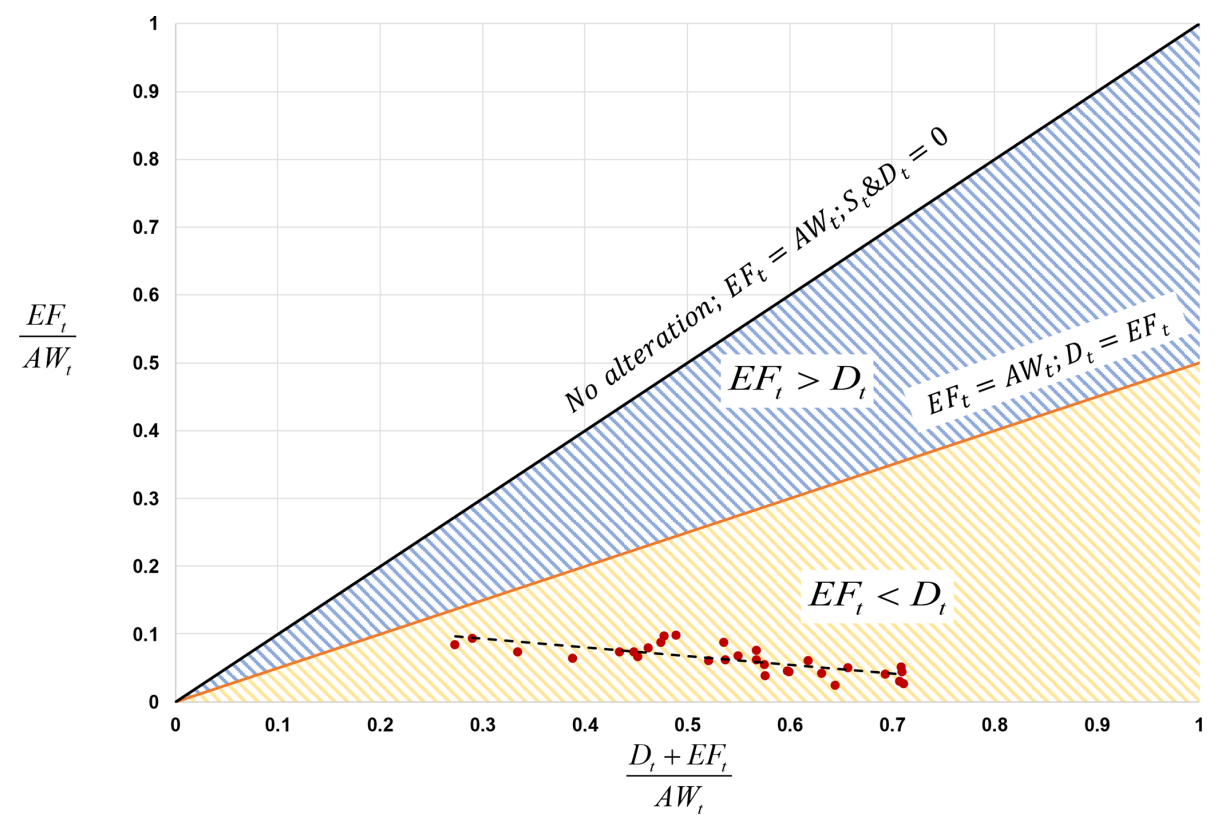

Figure 5. Modeling synthesizing flow alteration in the Budyko supply and demand framework: the ratio of environmental flow ("actual"; $\left.\mathrm{EF}_{t}\right)$ and the available water $\left(\mathrm{AW}_{t}\right)$ as a function of the ratio of the total demand for human and environmental flow ("demand"; $\left.D_{t}\right)$ and the available water ("supply"). Annual flows from Falls Lake, North Carolina (red dots), show human withdrawal for water supply is more than the downstream environmental flow release.

Rewriting $\mathrm{AW}_{t}$ as "supply", $D_{t}$ as "demand" and $R_{t}$ ("actual"), we develop the Budyko framework for the reservoir operation under SOP and hedging policy (Fig. 4). The SOP simply provides the asymptotes, the upper bounds, for the $R_{t} / \mathrm{AW}_{t}$ ("actual" / "supply") ratio. Figure 4 also demonstrates the developed framework for a hypothetical system for estimating the monthly releases (see Tables S1 and S2 in the Supplement for data and details). Increased hedging reduces the release and increases the storage and spill from the system. For demonstration, a linear hedging policy is applied. But the real-world system operation will have a complex nonlinear release policy, the data points are still expected to lie within the bounds. For systems with a small storage-todemand ratio, the spill portion on the left asymptote is expected to be much longer than a system with large storageto-demand ratio. Similarly, for systems with a large (small) storage-to-demand ratio, most data points are expected to lie below (on) the asymptote portion of the framework. Given that this framework in Fig. 4 is non-dimensional, we could analyze release to demand characteristics for reservoirs with competing purposes (e.g., hydroelectric vs. flood control) and synthesize how release patterns vary based on the demand-to-available water ratio across different type of systems. Similarly, one can also formulate the functional forms for a nonlinear hedging policy as Budyko equations, because the upper bounds are specified by the "supply and demand" relationship.

\subsection{Representing human demand and environmental flows in from reservoir operation}

Reservoir storages reduce runoff variability to meet the human demand, thereby resulting in substantial flow alterations (Wang et al., 2017). By adding a dedicated term, environmental flow, $\mathrm{EF}_{t}$, we rewrite the reservoir mass balance in Eq. (3).

$S_{t}=\mathrm{AW}_{t}-R_{t}-\mathrm{EF}_{t}-\mathrm{SP}_{t}$

Given our variable of interest here is $\mathrm{EF}_{t}$ ("actual"), we represent the "demand" as $R_{t}+\mathrm{EF}_{t}$ and available water, $\mathrm{AW}_{t}$, as "supply", which gives us a simple framework to visualize the ratio, environmental flow allocation $\mathrm{EF}_{t} / \mathrm{AW}_{t}$, which is specified by the $1: 1$ line. The term $1-\mathrm{EF}_{t} / \mathrm{AW}_{t}$ simply represents the alteration ratio at a given time step. The lower bound specifies only allocation $\left(R_{t} / \mathrm{EF}_{t}=0\right)$ for human demand and a slope of 0.5 indicates equal allocation for human need and ecological demand. For instance, if $R_{t} / \mathrm{EF}_{t}$ falls below the slope of 0.5 , it indicates significant flow alteration to meet human demand.

In the case of Falls Lake (Fig. 5), a major water supply reservoir in the triangle area in North Carolina (see Table S3 for data and additional details), it is evident that flow alteration is significant due to increased allocation for human demand since more data points lie below the equal allocation line. Using the proposed framework in Fig. 5, one could synthesize how a reservoir system with a large residence time (commonly known as degree of regulation) could affect 
flow alteration under arid and humid conditions. The negative linear trend indicates (Fig. 5) increased allocation for human use results in decreased environmental flow allocation. For instance, reservoirs in arid (humid) climates are typically larger to reduce the larger (smaller) interannual variability in runoff; hence, such systems are expected to have a higher (lower) degree of regulation. However, this synthesis of reservoir systems across different climatic regimes needs to be evaluated in the context of withdrawals for human use, their purpose, and the consumptive use associated with them. We argue the proposed framework could be useful for understanding the trade-off between water allocation for human use and downstream ecological requirements.

We argue that the Budyko supply and demand framework could also be considered for understanding the role of humans in altering the land-surface fluxes. As the supply and demand framework is based on conservation equations, it could be exploited for understanding and quantifying the spatial variability in land-surface fluxes under natural and human-altered landscapes. It is important to mention that the relationship between "Actual/Supply" and "Demand/Supply" could arise due to spurious correlation as they are shared by a common denominator term "Supply" (Benson, 1965; Brett, 2004). Hence, the relationship between the "Actual" and the "Demand" should be evaluated carefully by avoiding the spurious correlation. In Figs. 4 and 5, we provide an extension of the Budyko framework for understanding how land-surface fluxes are modified due to human influence. Understanding the key drivers that alter the spatial variability of land-surface fluxes using the modified and extended Budyko framework should help in identifying the relevant low-dimensional attributes that control the regional hydroclimate of human-altered watersheds and landscapes. For long-term evapotranspiration (ET), the aridity index is the control. For infiltration, it is the ratio of infiltration capacity to rainfall depth. For reservoir operation, it is the ratio of human water demand to available water in the reservoir. For environmental flows, it is the competition with human demand and available water. Thus, the low-dimensional attribute varies for each environmental issue. Further, extending the Budyko framework to include anthropogenic causes should enable the explicit decomposition and attribution of changes in land-surface fluxes at various temporal scales resulting from changes in local/regional hydroclimate or watershed-level modification. To refine existing hydroclimatologic models and datasets developed at the regional, continental, and global scales, a synthesis study is needed to understand how the land-surface response varies across natural and human-altered watersheds. Such a synthesis effort could also enable a systematic decomposition of watershedscale anthropogenic influences and large-scale climate effects in modulating land-surface fluxes at the global scale, providing a tribute to Budyko's legacy.

\section{Opportunities, challenges, and relevance to other hydrologic synthesis studies}

Emphasis on understanding the complex interactions and feedback between human and hydrological systems has renewed focus on "Socio-hydrology" (Sivapalan et al., 2012). The effects of water use, land use and land cover and other anthropogenic influences on watershed runoff and associated issues of non-stationarity have been referred to as the study of "Hydro-morphology" (Vogel, 2011). Vogel et al. (2015) argue that "to resolve the complex water problems that the world faces today, nearly every theoretical hydrologic model introduced previously is in need of revision to accommodate how climate, land, vegetation, and socioeconomic factors interact, change, and evolve over time." Study of interactions between humans and the earth system has also received considerable support from various agencies such as the National Science Foundation, the National Institute of Food and Agriculture, and the US Geological Survey, including targeted programs (e.g., NSF Solicitation 13-535, "Water Sustainability and Climate", NSF Solicitation 18-545, "Coupled Human-Natural Systems and Innovations in Food-EnergyWater Systems"). Thus, evolving the Budyko framework to better understand how land-surface responses vary under natural and human-altered landscapes will also support various ongoing studies on the effect of humans on hydrological systems.

Enhancements to the Budyko framework will also support other ongoing activities that focus on improving the ability to predict the hydrologic behavior of natural and ungauged watersheds. As competition for water increases, there has been increasing attention placed on the need for water availability information at ungauged locations, even in regions where water has not been considered in the past to be a limited resource. For these reasons, the decade from 2003 to 2012 was recognized by the International Association of Hydrological Sciences as the Prediction in Ungauged Basins (PUB) Decade (Sivapalan et al., 2003). Blöschl et al. (2013; Tables A7-A10) showed that several methods to predict streamflow in ungauged watersheds have been proposed; however, no one method has been universally accepted or demonstrated to work in all hydrologic settings. Other studies have evaluated predictability in ungauged basins at the global scale (Hrachowitz et al., 2013). Because the Budyko framework provides an approach for improving our understanding of ungauged basins, there is potential cross-fertilization in various ongoing studies for evaluating the extended Budyko framework and associated datasets, in order to support a range of global- and continental-scale hydrologic initiatives.

Another exciting aspect of the extension of the Budyko framework for considering anthropogenic influences concerns the development of hydrologic indicators for a wide range of purposes related to human effects. These include watershed classification, environmental permitting and a variety of water management activities. There is a continuing 
need for new hydrologic indicators, founded on the science of hydrology, for the purpose of watershed classification as expressed so nicely by Wagener et al. (2007). The development and plotting of nondimensional variables, analogous to the nondimensional variables proposed in Fig. 1, have a close association with the development of nondimensional hydroclimatic indicators for both natural (Weiskel et al., 2014) and human-dominated (Weiskel et al., 2007) hydrologic systems. For example, the aridity and runoff ratios, two commonly used nondimensional hydroclimatic indicators, arise naturally from the Budyko framework for natural watersheds. We anticipate that a wide range of new hydrologic indicators, founded on the science of hydrology, yet useful for water management and watershed classification, will arise from the types of studies envisioned here which extend the Budyko framework to accommodate anthropogenic influences.

One substantial challenge in evaluating the Budyko framework under human-altered landscapes would be the availability of data on hydroclimate, storages, and human influences, including water withdrawal and land-use changes, reservoir storages and releases, at different spatio-temporal scales. For example, the monthly change in total water storage is a critical component of accurate assessments of landsurface fluxes, particularly in regions of high anthropogenic influence where storage is affected by pumping of groundwater resources, or conversion of surface water to evapotranspiration through diversion for irrigation. In addition to the tremendous challenges relating to data availability, there is the open research question of how we can capture the complexity of human-water systems with a low-dimensional, parsimonious modeling approach. One approach involves a gradual refinement of model features - a top-down approach - as needed (Zhang et al., 2008; Sivapalan et al., 2003). Another strategy involves development of critical datasets and the subsequent addition of model features as the spatiotemporal scale of the data permits. Such a global synthesis effort will require global-scale datasets from a variety of sources, including remotely sensed data. The selection of appropriate data at this scale presents challenges in balancing spatial resolution, uncertain data accuracy, and consistency among the considered datasets. Findings from another synthesis study titled "Water Availability for Ungaged Basins" revealed that, as various hydrologic modeling communities converge towards continental-domain hydrologic models, these communities will encounter similar limitations and challenges (Archfield et al., 2015). It is our hope and contention that the Budyko framework can provide a unifying perspective for bridging gaps in hydrologic data availability and model resolution over a wide range of spatial and temporal scales. As shown in this opinion article, the Budyko framework can also be modified beyond the traditional longterm water balance, to improve basic understanding of how the land-surface responses - runoff and evapotranspiration vary across natural and human-altered landscapes.
Data availability. The data used in this paper are provided in the Supplement and supported by the references.

Supplement. The supplement related to this article is available online at: https://doi.org/10.5194/hess-24-1975-2020-supplement.

Author contributions. AS and DW designed and conducted the analyses. SA and MR wrote the paper. RMV provided the perspectives and commentary on Budyko's contribution to hydrology. AM performed the NLDAS-2 analysis and Mukhopadhyay provided the analyses on the flow alteration.

Competing interests. The authors declare that they have no conflict of interest.

Acknowledgements. This research was funded in part under award EAR-1823111 from the National Science Foundation (NSF) and from US Geological Survey (USGS) Powell Center Working Group Project "A global synthesis of land-surface fluxes under natural and human-altered watersheds using the Budyko framework". We are also grateful for the comments on the manuscript by HESS editor Erwih Zehe, two USGS reviewers Peter Weiskel and David Wolock, open review by Wouter Berghuijs, and two anonymous reviewers. Any use of trade, firm, or product names is for descriptive purposes only and does not imply endorsement by the US Government.

Financial support. This research has been supported by the National Science Foundation, Directorate for Geosciences (grant no. EAR-1823111) and the United States Geological Survey (grant no. G18AC0003).

Review statement. This paper was edited by Erwin Zehe and reviewed by two anonymous referees.

\section{References}

Abatzoglou, J. T. and Ficklin, D. L.: Climatic and physiographic controls of spatial variability in surface water balance over the contiguous United States using the Budyko relationship, Water Resour. Res., 53, 7630-7643, https://doi.org/10.1002/2017WR020843, 2017.

Allaire, M. C., Kroll, C. N., and Vogel, R. M.: The hydromorphology of an urbanizing watershed using multivariate elasticity, Adv. Water Resour., 86, 147-154, 2015.

Archfield, S. A., Clark, M., Arheimer, B., Hay, L. E., Farmer, W. H., McMillan, H., Seibert, J., Kiang, J. E. , Wagener, T., Bock, A., Hakala, K., Andréassian, V., Attinger, S., Viglione, A., Knight, R. R., and Over, T. M.: Accelerating advances in continental domain hydrologic modeling, Water Resour. Res., 51, 1007810091, https://doi.org/10.1002/2015WR017498, 2015. 
Archfield, S. A., Hirsch, R. M., Viglione, A., and Blöschl, G.: Fragmented patterns of flood change across the United States, Geophys. Res. Lett., 43, 10-232, https://doi.org/10.1002/2016GL070590, 2016.

Barros, A. P., Duan, Y., Brun, J., and Medina, M. A.: Flood nonstationarity in the Southeast and Mid-Atlantic Regions of the United States, J. Hydraul. Eng., 19, 05014014, https://doi.org/10.1061/(ASCE)HE.1943-5584.0000955, 2014.

Benson, M. A. : Spurious correlation in hydraulics and hydrology, J. Hydraul. Div., 91, 35-42, 1965.

Blöschl, G., Sivapalan, M., Savenije, H., Wagener, T., and Viglione, A.: Runoff prediction in ungauged basins, in: Synthesis across processes, places and scales, Cambridge University Press, Cambridge, 2013.

Brett, M. T.: When is a correlation between non-independent variables "spurious"?, Oikos, 105, 647-656, 2004.

Budyko, M. I.: The Heat Balance of the Earth's Surface, translated from Russian by N. A. Stepanova, US Dep. of Commer., Washington, D.C., 259 pp., 1958.

Budyko, M. I.: Climate and Life, Academic, New York, 508 pp., 1974.

Chen, X., Alimohammadi, N., and Wang, D.: Modeling interannual variability of seasonal evaporation and storage change based on the extended Budyko framework, Water Resour. Res., 49, 60676078, https://doi.org/10.1002/wrcr.20493, 2013.

Creed, I. F., Spargo, A. T., Jones, J. A., Buttle, J. M., Adams, M. B., Beall, F. D., Booth, E. G., Campbell, J. L., Clow, D., Elder, K., Green, M. B., Grimm, N. B., Miniat, C., Ramlal, P., Saha, A., Sebestyen, S., Spittlehouse, D., Sterling, S., Williams, M. W., Winkler, R., and Yao, H.: Changing forest water yields in response to climate warming: results from long-term experimental watershed sites across North America, Global Change Biol., 20, 3191-3208, https://doi.org/10.1111/gcb.12615, 2014.

Das, P., Patskoski, J., and Sankarasubramanian, A.: Modeling the irrigation withdrawals over the coterminous US using a hierarchical modeling approach, Water Resour. Res., 54, 3769-3787, https://doi.org/10.1029/2017WR021723, 2018.

Dieter, C. A., Maupin, M. A., Caldwell, R. R., Harris, M. A., Ivahnenko, T. I., Lovelace, J. K., Barber, N. L., and Linsey, K. S.: Estimated use of water in the United States in 2015, US Geological Survey Circular 1441, US Geological Survey, Reston, VA, p. 65, https://doi.org/10.3133/cir1441, 2018.

Dooge, J. C. I.: Sensitivity of runoff to climate change: a Hortonian approach, B. Am. Meteorol. Soc., 73, 2013-2024, 1992.

Dooge, J. C. I., Bruen, M., and Parmentier, B.: A simple model for estimating the sensitivity of runoff to long-term changes in precipitation without a change in vegetation, Adv. Water Resour., 23, 153-163, 1999.

Draper, A. J. and Lund, J. R.: Optimal hedging and carryover storage value, J. Water Resour. Plan. Manage., 130, 83-87, 2004.

Entekhabi, D., Ghassem, R. A., Betts, A. K., Beven, K. J., Bras, R. L., Duffy, C. J., Dunne, T., Koster, R. D., Lettenmaier, D. P., McLaughlin, D. B., ShuttIeworth, W. J., van Genuchten, M. T., Wei, M., and Wood, E. F.: An agenda for land surface hydrology research and a call for the Second International Hydrological Decade, B. Am. Meteorol. Soc., 80, 2043-2058, 1999.

Gao, Y., Vogel, R. M., Kroll, C. N., Poff, N. L., and Olden, J. D.: Development of representative indicators of hydrologic alteration, J. Hydrol., 374, 136-147, 2009.
Harman, C. and Troch, P. A.: What makes Darwinian hydrology "Darwinian"? Asking a different kind of question about landscapes, Hydrol. Earth Syst. Sci., 18, 417-433, https://doi.org/10.5194/hess-18-417-2014, 2014.

Hirsch, R. M. and Archfield, S. A.: Flood trends: Not higher but more often, Nat. Clim. Change, 5, 198-199, 2015.

Hrachowitz, M., Savenije, H. H. G., Blöschl, G., McDonnell, J. J., Sivapalan, M., Pomeroy, J. W., Arheimer, B., Blume, T., Clark, M. P., Ehret, U., Fenicia, F., Freer, J. E., Gelfan, A., Gupta, H. V., Hughes, D. A., Hut, R. W., Montanari, A., Pande, S., Tetzlaff, D., Troch, P. A., Uhlenbrook, S., Wagener, T., Winsemius, H. C., Woods, R. A., Zehe, E., and Cudennec, C.: A decade of Predictions in Ungauged Basins (PUB) - a review, Hydrolog. Sci. J., 58, 1198-1255, 2013.

Jaramillo, F.,and Destouni, G.: Local flow regulation and irrigation raise global human water consumption and footprint, Science, 350, 1248-1251, https://doi.org/10.1126/science.aad1010, 2015.

Jiang, C., Xiong, L., Wang, D., Liu, P., Guo, S., and Xu, C. Y.: Separating the impacts of climate change and human activities on runoff using the Budyko-type equations with time varying parameters, J. Hydrol., 522, 326-338, https://doi.org/10.1016/j.jhydrol.2014.12.060, 2015.

Koster, R. D. and Suarez, M. J.: A simple framework for examining the interannual variability of land surface moisture fluxes, J. Climate, 12, 1911-1917, 1999.

Kustu, M. D., Fan, Y., and Rodell, M.: Possible link between irrigation in the U.S. High Plains and increased summer streamflow in the Midwest, Water Resour. Res., 47, W03522, https://doi.org/10.1029/2010WR010046, 2011.

Li, D., Pan, M., Cong, Z., Zhang, L., and Wood, E.: Vegetation control on water and energy balance within the Budyko framework, Water Resour. Res., 49, 969-976, 2013.

Malikpour, I. and Villarini, G.: The changing nature of flooding across the central United States, Nat. Clim. Change, 5, 250-254, 2015.

Memon, R. A., Leung, Y. C., and Liu, C. H.: A review on the generation, determination and mitigation of urban heat island, J. Environ. Sci., 20, 120-128, 2008.

Milly, P. C. D.: Climate, soil water storage, and the average annual water balance, Water Resour. Res., 30, 2143-2156, https://doi.org/10.1029/94WR00586, 1994.

Padrn, R. S., Gudmundsson, L., Greve, P., and Seneviratne, S. I. : Large-scale controls of the surface water balance over land: Insights from a systematic review and meta-analysis, Water Resour. Res., 53, 9659-9678, https://doi.org/10.1002/2017WR021215, 2017.

Petersen, T., Devineni, N., and Sankarasubramanian, A.: Seasonality of monthly runoff over the continental United States: Causality and relations to mean annual and mean monthly distributions of moisture and energy, J. Hydrol., 468, 139-150, 2012.

Petersen, T., Devineni, N., and Sankarasubramanian, A.: Monthly hydroclimatology of the continental United States, Adv. Water Resour., 114, 180-195, 2018.

Price, K.: Effects of watershed topography, soils, land use, and climate on baseflow hydrology in humid regions: a review, Prog. Phys. Geogr., 35, 465-492, 2011.

Prosdocimi, I., Kjeldsen, T. R., and Miller, J. D.: Detection and attribution of urbanization effect on flood extremes using nonstation- 
ary flood-frequency models, Water Resour. Res., 51, 4244-4262, 2015.

Rice, J. S., Emanuel, R. E., Vose, J. M., and Nelson, S. A.: Continental U.S. streamflow trends from 1940 to 2009 and their relationships with watershed spatial characteristics, Water Resour. Res., 51, 6262-6275, https://doi.org/10.1002/2014WR016367, 2015.

Rodell, M., Houser, P. R., Jambor, U., Gottschalck, J., Mitchell, K., Meng, C.-J., Arsenault, K., Cosgrove, B., Radakovich, J., Bosilovich, M., Entin, J. K., Walker, J. P., Lohmann, D., and Toll, D.: The Global Land Data Assimilation System, B. Am. Meteorol. Soc., 85, 381-394, 2004.

Roderick, M. L. and Farquhar, G. D.: A simple framework for relating variations in runoff to variations in climatic conditions and catchment properties, Water Resour. Res., 47, W00G07, https://doi.org/10.1029/2010WR009826, 2011.

Rui, H.: README Document for Global Land Data Assimilation System Version 2 (GLDAS-2) Products, GES DISC, available at: https://data.mint.isi.edu/files/raw-data/GLDAS_NOAH025_M. 2.0/doc/README_GLDAS2.pdf (last access: 6 August 2019), 2011.

Sankarasubramanian, A. and Vogel, R. M.: Annual hydroclimatology of the United States, Water Resour. Res., 38, 1083, https://doi.org/10.1029/2001WR000619, 2002.

Sankarasubramanian, A. and Vogel, R. M.: Hydroclimatology of the continental United States, Geophys. Res. Lett., 30, 1363, https://doi.org/10.1029/2002GL015937, 2003.

Sankarasubramanian, A., Vogel, R. M., and Limbrunner, J. F.: Climate elasticity of streamflow in the United States, Water Resour. Res., 37, 1771-1781, 2001.

Sankarasubramanian, A., Sabo, J. L., Larson, K. L., Seo, S. B., Sinha, T., Bhowmik, R., Vidal, A. R., Kunkel, K., Mahinthakumar, G., Berglund, E. Z., and Kominoski, J.: Synthesis of public water supply use in the United States: Spatio-temporal patterns and socio-economic controls, Earth's Future, 5, 771-788, https://doi.org/10.1002/2016EF000511, 2017.

Sivapalan, M., Takeuchi, K., Franks, S. W., Gupta, V. K., Karambiri, H., Lakshmi, V., Liang, X., McDonnell, J. J., Mendiondo, E. M., O'Connell, P. E., Oki, T., Pomeroy, J. W., Schertzer, D., Uhlenbrook, S., and Zehe, E.: IAHS Decade on Predictions in Ungauged Basins (PUB), 2003-2012: Shaping an exciting future for the hydrological sciences, Hydrolog. Sci. J., 48, 857-880, 2003.

Sivapalan, M., Savenije, H. H., and Blöschl, G.: Socio-hydrology: A new science of people and water, Hydrol. Process., 26, 12701276, 2012.

Small, D., Islam, S., and Vogel, R. M.: Trends in precipitation and streamflow in the eastern U.S.: Paradox or perception?, Geophys. Res. Lett., 33, L03403, https://doi.org/10.1029/2005GL024995, 2006.

Vogel, R. M.: Hydromorphology, J. Water Res. Plan. Manage., 137, 147-149, 2011.

Vogel, R. M., Yaindl, C., and Walter, M.: Nonstationarity: Flood magnification and recurrence reduction factors in the United States, J. Am. Water Resour. Assoc., 47, 464-474, 2011.

Vogel, R. M., Lall, U., Cai, X., Rajagopalan, B., Weiskel, P., Hooper, R. P., and Matalas N. C.: Hydrology: The interdisciplinary science of water, Water Resour. Res., 51, 4409-4430, https://doi.org/10.1002/2015WR017049, 2015.
Wagener, T., Sivapalan, M., Troch, P., and Woods, R.: Catchment Classification and Hydrologic Similarity, Geogr. Compass, 1, 901-931, https://doi.org/10.1111/j.1749-8198.2007.00039.x, 2007.

Wang, C., Wang, S., and Fu, B.: Advances in hydrological modeling with the Budyko framework: A review, Prog. Phys. Geogr., 40, 409-430, 2016.

Wang, D.: A new probability density function for spatial distribution of soil water storage capacity leads to SCS curve number method, Hydrol. Earth Syst. Sci., 22, 6567-6578, https://doi.org/10.5194/hess-22-6567-2018, 2018.

Wang, D. and Hejazi, M.: Quantifying the relative contribution of the climate and direct human impacts on mean annual streamflow in the contiguous United States, Water Resour. Res., 47, W00J12, https://doi.org/10.1029/2010WR010283, 2011.

Wang, D. and Tang, Y.: A one-parameter Budyko model for water balance captures emergent behavior in Darwinian hydrologic models, Geophys. Res. Lett., 41, 4569-4577, https://doi.org/10.1002/2014GL060509, 2014.

Wang, W., Li, H.-Y., Leung, L. R., Yigzaw, W., Zhao, J., Lu, H., Blöschl, G.: Nonlinear filtering effects of reservoirs on flood frequency curves at the regional scale, Water Resour. Res., 53, 8277-8292, https://doi.org/10.1002/2017WR020871, 2017.

Weiskel, P. K., Vogel, R. M., Steeves, P. A., Zarriello, P. J., DeSimone, L. A., and Ries III, K. G.: Water-use regimes: Characterizing direct human interaction with hydrologic systems, Water Resour. Res., 43, W04402, https://doi.org/10.1029/2006WR005062, 2007.

Weiskel, P. K., Wolock, D. M., Zarriello, P. J., Vogel, R. M., Levin, S. B., and Lent, R. M.: Hydroclimatic regimes: a distributed water-balance framework for hydrologic assessment, classification, and management, Hydrol. Earth Syst. Sci., 18, 3855-3872, https://doi.org/10.5194/hess-18-3855-2014 2014.

Yang, D., Sun, F., Liu, Z., Cong, Z., Ni, G., and Lei, Z.: Analyzing spatial and temporal variability of annual water-energy balance in nonhumid regions of China using the Budyko hypothesis, Water Resour. Res., 43, W04426, https://doi.org/10.1029/2006WR005224, 2007.

Yang, H., Yang, D., and $\mathrm{Hu}$, Q.: An error analysis of the Budyko hypothesis for assessing the contribution of climate change to runoff, Water Resour. Res., 50, 9620-9629, https://doi.org/10.1002/2014WR015451, 2014.

Zehe, E., Loritz, R., Jackisch, C., Westhoff, M., Kleidon, A., Blume, T., Hassler, S. K., and Savenije, H. H.: Energy states of soil water - a thermodynamic perspective on soil water dynamics and storage-controlled streamflow, Hydrol. Earth Syst. Sci., 23, 971 987, https://doi.org/10.5194/hess-23-971-2019, 2019.

Zhang, L., Hickel, K., Dawes, W. R., Chiew, F. H. S., Western, A. W., and Briggs, P. R.: A rational function approach for estimating mean annual evapotranspiration, Water Resour. Res., 40, W02502, https://doi.org/10.1029/2003WR002710, 2004.

Zhang, L., Potter, N., Hickel, K., Zhang, Y. Q., and Shao, Q. X.: Water balance modeling over variable time scales based on the Budyko framework - Model development and testing, J. Hydrol., 360, 117-131, 2008. 